\title{
Mapping the Surface Changes in the Area of East Port-Said, Egypt Using Multi-Temporal and Multi-Sensors Remote Sensing Data
}

\author{
Ahmed Gaber ${ }^{1}$, Mohamed H. Geriesh ${ }^{2}$, Shams El-Din Shaheen ${ }^{1}$, Mohamed \\ A.El-Fattah ${ }^{1}$ \\ ${ }^{I}$ Geology Department, Faculty of Science, Port-Said University, Egypt \\ ${ }^{2}$ Geology Department, Faculty of Science, Suez Canal University, Ismailia, Egypt.
}

\begin{abstract}
The area of East Port-Said is recently regarded as one of the most important Egyptian potential area that helps improving the Egyptian's national income. The area is considered as one of the Egyptian good areas for reclamation, and ready to grow as a new one-million citizen-city with full life necessities. East PortSaid area now includes a famous harbour for containers and transit-trade. However, many industrial, agricultural and touristic projects are strongly aimed to be initiated and established in such city. Accordingly, the area requires many intensive and detailed studies to evaluate and assess the environmental changes on the surface sediments. So the objectives of this study are to define the land units and changes associated with land use and land cover properties (LULC) by multi-temporal and multi-sensor Remote Sensing (RS) data.
\end{abstract}

Keywords: East Port-Said, Environmental Changes, LU/LC, Multi-temporal, multi-sensor Remote Sensing (RS) data

\section{Introduction}

Environmental change is facing a critical problem due to several factors such as increasing population, unused water resources correctly, environmental pollution and bad land use planning. In the present day, East Port-Said area is one of the promising areas that hosted ongoing mega-project and can be used to decrease population density in Port-Said Governorate. Thus the main objective of this study is to define the land units and changes at East Port-Said area which associated with land use and land cover (LULC) properties by integrating Remote Sensing (RS) and Geographic Information System (GIS) methodologies. Office data editing was performed and followed by images analysis of satellite data .A field work was performed to check the different spectral and extracted land units. Field observations were compatible with the area and its spatial variability. Several studies have been conducted to cover the geology of Sinai especially on the Late Quaternary evolution and geo-environmental changes in the frame of sustainable development. The study area is subjected to land subsides at average rate of about $0.5 \mathrm{~cm} / \mathrm{yr}$ and the sea level could rise $50 \mathrm{~cm}$ by the year 2100 [31]. In $1996 \mathrm{a}$ project of core samples drilled by an engineering company as a part of the feasibility study of El-Salam Canal project, the study of these samples led to improve understanding of the geology of Late Quaternary along the study area and the related paleo-shore lines and then to construct the Late Quaternary sequence stratigraphy in relation to sea level changes [8]. More recently, the satellite remote sensing data in addition to Geographic Information Systems (GIS) offer an excellent alternative to conventional mapping techniques in investigating, monitoring, mapping rapid land use (activities) / land cover (resources) (LU / LC) changes and assessing geohazards areas. It was an attempt to forecasting the human impact on this coastal strip after the construction of the Eastern Harbor, at Port-Said, with possible extension to industrial, shipping and logistic activities on the expense of the traditional fish breeding, agriculture and solar salt activities.

\section{The Study Area}

The study area covers the entire sector lies between the Longitudes: $32^{\circ} 18^{`} \& 32^{\circ} 38^{`}$ and Latitudes: $31^{\circ}$ $01^{\circ} \& 31^{\circ} 14^{`}$.It covers a polygonal land-surface area of $\cong 380 \mathrm{~km}^{2}$ extending from the western tip of El-Bardawil Lagoon in the east, and extends westwards till the eastern bank of East Port-Said of the Suez Canal. El QantaraEl Arish asphaltic road constitutes the southern border of the study area, whereas the Mediterranean shoreline forms the northern border (Fig 1). It is an integral part of the ancient Nile Delta, cuts from the proper delta after excavating the Suez Canal in 1869 [31]. It has a concavo-convex shoreline configuration that is about $39 \mathrm{~km}$ long [4] [20]. The north-western corner of the East Port-Said area, south of Port-Fouad and directly east of the Suez Canal, is covered by El-Mallaha lagoon. It occupies a large triangle area of about $56 \mathrm{~km} 2$ with a $14 \mathrm{~km}$ base and up to an $8 \mathrm{~km}$ maximum width. El-Mallaha lagoon is filled with hyper-saline water all year. The Mediterranean Sea is connected to this lagoon by a small entrance near Port-Fouad and other shallow tidal inlets [11]. El-Mallaha lagoon has shallow depth ranging from 0.15 to $0.5 \mathrm{~m}$ and its salinity is higher than that of the 
Mediterranean Sea [20]. The East Port-Said is an extensive mud flat and covered by salt crust with thickness of 5 to $20 \mathrm{~cm}$ [9]. The Study area divided into three geomorphic units, the beach, the northern strand plain and a southern delta plain [8]. The beach has a NW-SE trend; it is a low slopped, smooth sandy beach, with no anthropogenic structures, except at the western part [20]. The only engineering structures built coast are the 7.7 and $2.0 \mathrm{~km}$ jetties constructed to protect the inlet at Port Said and the East Port Said Harbor, respectively [4]. The strand plain is a sandy one trending NW-SE, with $35 \mathrm{~km}$ long and varies in width from $1 \mathrm{~km}$ in the east to $12.5 \mathrm{~km}$ in the west. It is covered from the west by El-Mallaha lagoon. Toward the east, it consists of bundles of low accretional beach ridges (about 18 ridge), a few tens of centimeters $(20-30 \mathrm{~cm}$ ) to about $1.5 \mathrm{~m}$ higher than the surroundings [8] [15]. The Pelusium is a city in the extreme eastern Nile Delta of Egypt, $3.8 \mathrm{~km}$ to the south of the Mediterranean coast, about $32 \mathrm{~km}$ southeast of Port Said and $23 \mathrm{~km}$ east of the Suez Canal. It was a fortified port coastal city; its history possibly begins after the Persian invasions of Egypt from about 6th or 7th Century B.C. [15] [30].

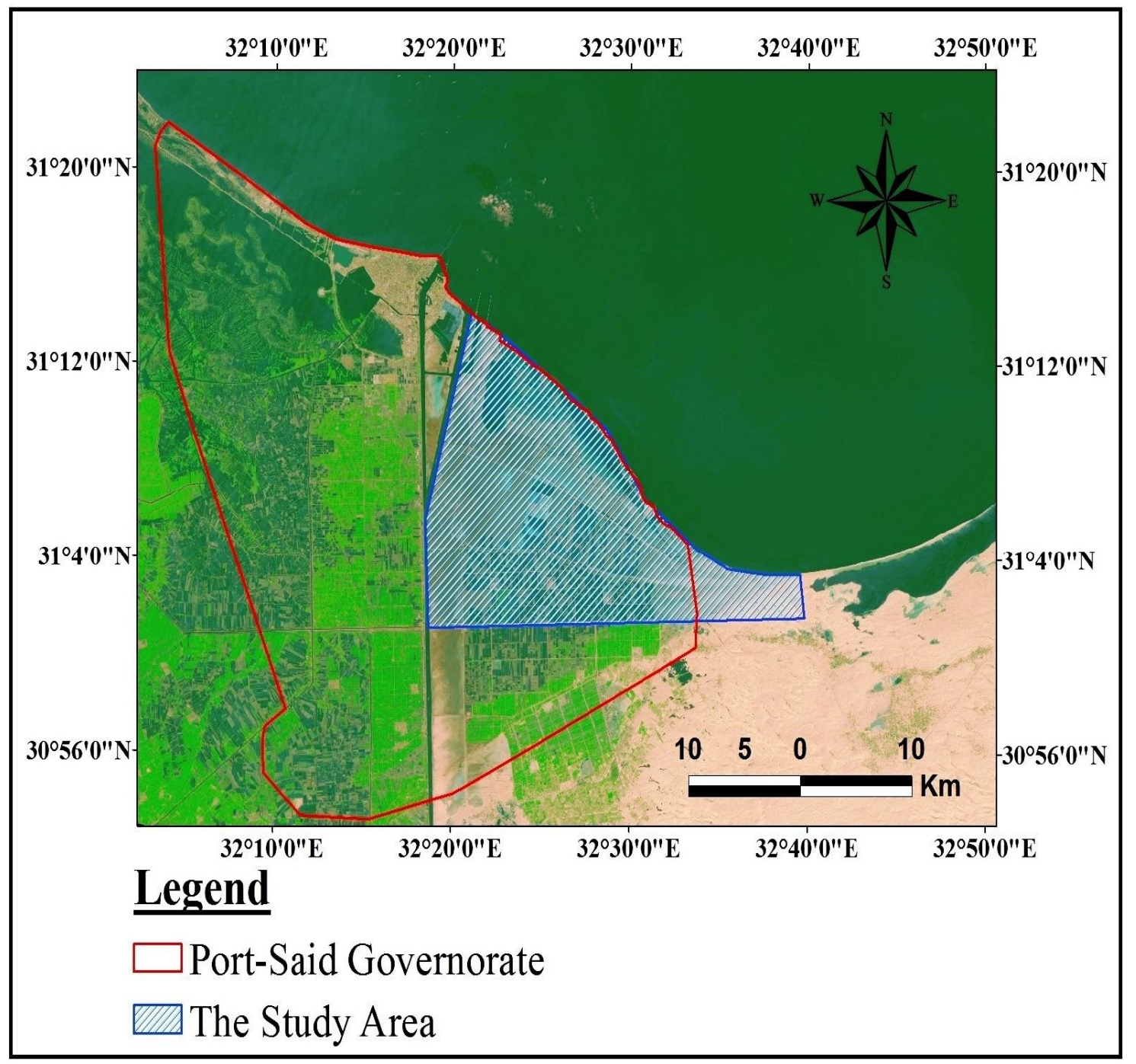

Fig (1): Location map of East Port-Said Area.

\subsection{Data characteristics:}

\section{Data and methodology}

Images from two sensors were utilized in this work. Two sets of Landsat scenes acquired on 20-Sep1984 (was collected from the Thematic Mapper on Landsat 5) and 29-Jan-2015 (was collected from the enhanced Thematic Mapper on Landsat 8) represent the optical data, of which the first six reflective bands (1-5 and 7) with a spatial resolution of $28.5 \mathrm{~m}$ and the panchromatic band 8 with a $14.25 \mathrm{~m}$ pixel resolution were used. The microwave dataset is a radarsat-1 (C-band, HH-polarization and descending orbit) Synthetic Aperture Radar (SAR) scene with a pixel size of $12.5 \mathrm{~m} \mathrm{x} 12.5 \mathrm{~m}$ that was acquired on 2010 . The two types of data (Optical and Radarsat data) basically one scene of each was enough as they covered the entire study area. 


\subsection{Image processing:}

\subsubsection{Image enhancement:}

Image enhancement is utilized to improve the visual interpretability of an image by increasing the apparent distinction between the features. The process of visually interpreting digitally enhanced imagery attempts to optimize the complementary abilities of the human mind and the computer [29]. We used a wide variety of image enhancement techniques to improve the clarity of land use/land cover changes that occurred following the large-scale development projects on the study area. Enhancement techniques can generally be divided into either pixel-to-pixel comparisons or post-classification comparisons [22].

\subsubsection{Band Ratio:}

Ratioing is considered to be a relatively rapid means of identifying areas of change [17] [18] [24] [34] [36]. Band ratio images enhance spectral differences between rocks and suppress topographic effects [5] [27].

\subsubsection{Principle Component Analysis (PCA):}

PCA was used to compress multi-channel image data by calculating a new coordinate system in which the first new axis (the first principle component) maximized the variance of the data along that axis. The second principle component (PC) is orthogonal to the first and has the second greatest variance and so on. The data are de-correlated and it was found that most of the image variance is confined to the first few channels. If one just considers the first few PCs and ignores PCs that do not contribute very much in the description of the data variance, PCA can be used to compress data into more interpretable forms. One of the important features of PCA is that it produces totally uncorrelated images and thereby removes redundancy in the original data sets [7]. Data are de-correlated by transforming DN distributions around sets of new multi-spaced axes. It should be noted that PCA does not reduce the amount of information; each PC grouping explains the maximum amount of variance in data. This procedure increases the spectral discrimination capability among terrestrial materials. PCA seemed the most reliable technique to obtain significant results [25]. It is a widely applied technique in remote sensing image enhancement [26]. PCA was used to increase the spectral discrimination capability among terrestrial materials [4]. In addition, an examination of the band correlation matrix produced from the PCA of all original bands indicated that false color composites can be utilized to visualize land use/land cover changes along the northern part of the Nile Delta without any enhancement processes [6]. In order to minimize the whole variance in the scene from different band data, standardized PCA were used [30]. In fact, for multi-temporal change detection, standardized principal components are more accurate than their non-standardized counterparts [7] [13]. Multi-temporal Landsat Thematic Mapper data were analyzed by PCA to derive information about the different spectral features in order to help in the monitoring of sedimentation and algal production processes [25].

\subsubsection{Data Fusion (Resolution merge):}

The data fusion method was performed by applying image sharpening algorithm that is implemented in ENVI image processing software [35]. This is a popular data fusion method that is normally used to sharpen a low resolution multi-band image with a high resolution panchromatic band. However, it can also be used for fusing optical and microwave data [37].

The data fusion was performed in the following steps [14]:

1. Speckle reduction of the SAR image using a Lee-enhanced filter.

2. Data scaling of the SAR image from 16 bit to 8 bit.

3. Georeferencing of the SAR and Landsat ETM+ images to a common UTM coordinate system

4. Performing an image transformation to Landsat ETM+ bands $1-5$ and 7 with panchromatic band (high resolution).

Replacing panchromatic band with the radarsat image as the high resolution component.

\subsection{Image Classification:}

Image classification is the most widely used technique in various remote sensing applications for extraction of target thematic information. In the context of present study, the land use / land cover (LULC) is the main target which is to be extracted using a suitable classification method for LULC change detection. Basically, image classification is a mapping process to generalize the image pixels into meaningful groups each resembling different land category [19]. This practice is based on conventional statistical techniques such as supervised and unsupervised classification where the classes are supervised by analyst and are not supervised (i.e. fully automatic based on spectral values) respectively.

3.3.1 Unsupervised Classification: An unsupervised classification using a K-means clustering algorithm (with 10 initial classes and five iterations) was performed on East Port-Said area using optical data (1984 and 2015) and hybrid images (ETM+/Radarsat-1) with respectively six bands as input data. 


\subsubsection{Supervised Classification:}

Supervised maximum likelihood classification (MLC) was used for detecting land cover classes [31]. Once a sufficient number of such spectral subclasses were acquired for all information classes, a maximum likelihood classification was performed with the full set of refined spectral classes [21]. Despite the fact that MLC is a statistically complicated technique to classify images for change detection, it was considered to be the most effective method for supervised classification [3] [16] [33]. It requires intensive calculations, so it has the disadvantage of requiring more computer resources than do most of the other techniques used for supervised classification. Maximum likelihood classification considers not only the mean or average values in assigning classification but also the variability of brightness values in each class. Maximum likelihood supervised classification was applied to optical images (1984 and 2015) and hybrid image (ETM+/Radarsat-1) using field investigation information collected from more than 30 ground checkpoints of East Port-Said area. Extraction of the seven major classes from optical images (1984 and 2015) and hybrid image (ETM+/Radarsat-1) was assisted by image classification.

\subsection{Image Processing:}

\section{IV. results and discussion}

\subsubsection{Best three bands combination:}

The color composition of the Landsat data is used for displaying the data in image files, since the data file values of an image are related to the brightens values of color display. The analyst can assign bands to be displayed with any of the three colors: red, green and blue (R, G and B). For example, a natural color simulated image will approximate the colors that would appear to a human observer of the scene. While false color allows the analyst to view the bands of data that would not appear to a human. The composite image data for the years 1984 and 2015 are bands 7, 4, 2 for red, green and blue in (Figure 2).

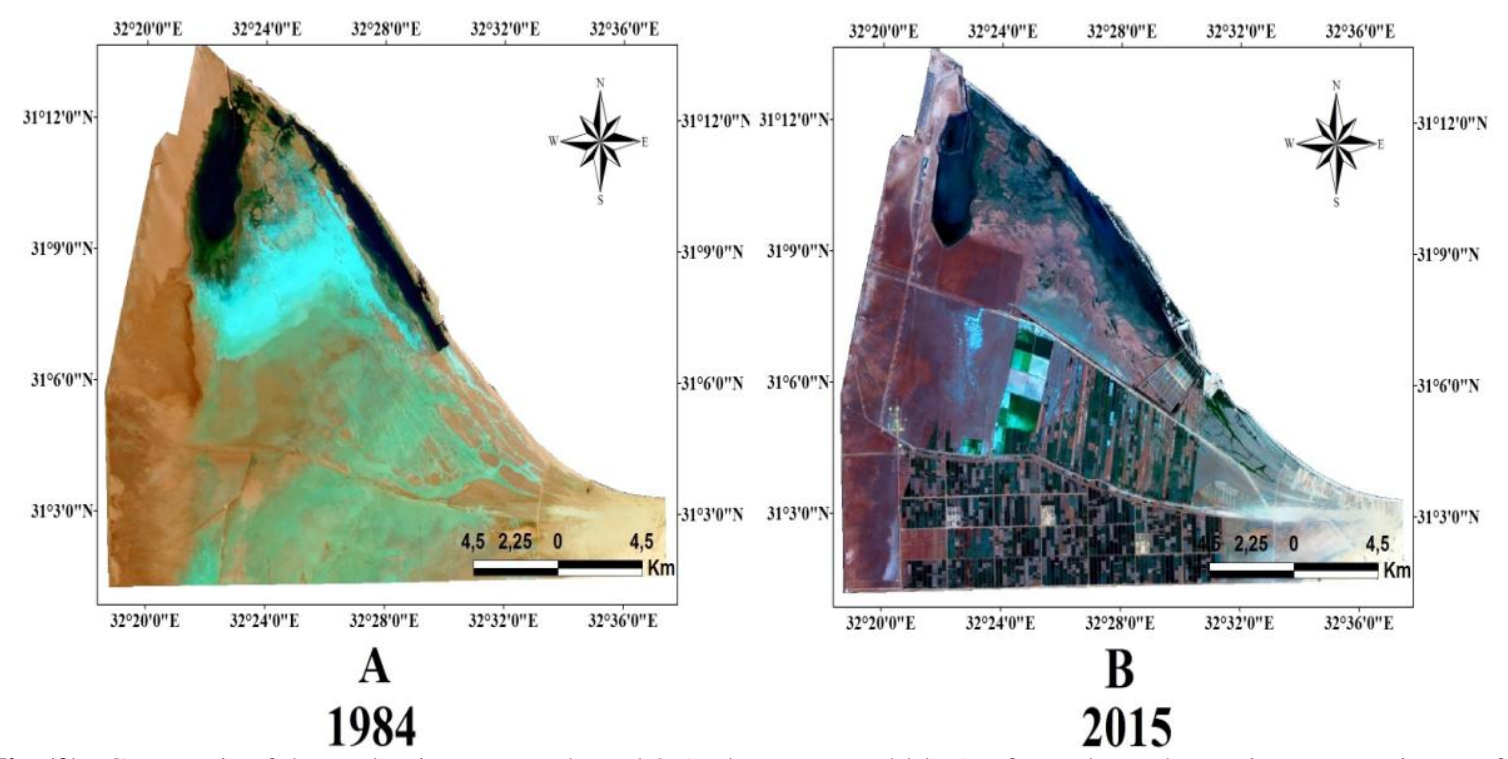

Fig (2): Composite false color images 7, 4, and 2 (red, green, and blue) of Landsat Thematic Mapper image for 1984 (A) and Landsat ETM+ for 2015 (B)

\subsubsection{Image enhancement: \\ 4.1.2.1 Band Ratio:}

Band Ratio is used to enhance the spectral differences between bands and to reduce the effects of topography. Dividing one spectral band by another produces an image that provides relative band intensities. The image enhances the spectral differences between bands. ENVI software can output band ratio images in either floating-point (decimal) format or byte data format. Floating-point format is the default. You may combine three ratios into a color-ratio-composite (CRC) image to determine the approximate spectral shape for each pixel's spectrum. To calculate band ratios, we specify a numerator band and a denominator band. The band ratio is the numerator divided by the denominator. ENVI checks for division-by-zero errors and sets them to 0 . ENVI also allows you to calculate multiple ratios and output them as multiple bands in one file [11]. Spectral data can be extracted from the multispectral images and the variable topographic features [22]. Bands 7, 4 and 2 represented by red, green and blue in Fig (3) were used from the composite ETM image data for the years 1984 and 2015. False color composite helps us to visualize land use/land cover changes without enhancement processes. Ratio images are derived by simple pixel-by-pixel division of digital values. This division also 
minimized differences in illumination, reduced the effects of shadows, emphasized differences in spectral reflectance and conveys the spectral characteristics of image features. The most appropriate band ratios used so far were 7/4, 7/2 and 4/2 which are equivalent to red, green and blue, respectively [20]. El-Mallaha Lagoon, which appears black in 1984 and 2015 (Fig 3). The cultivated lands appear brown. Fish farms are distributed between El-Mallaha Lagoon and the cultivated land.

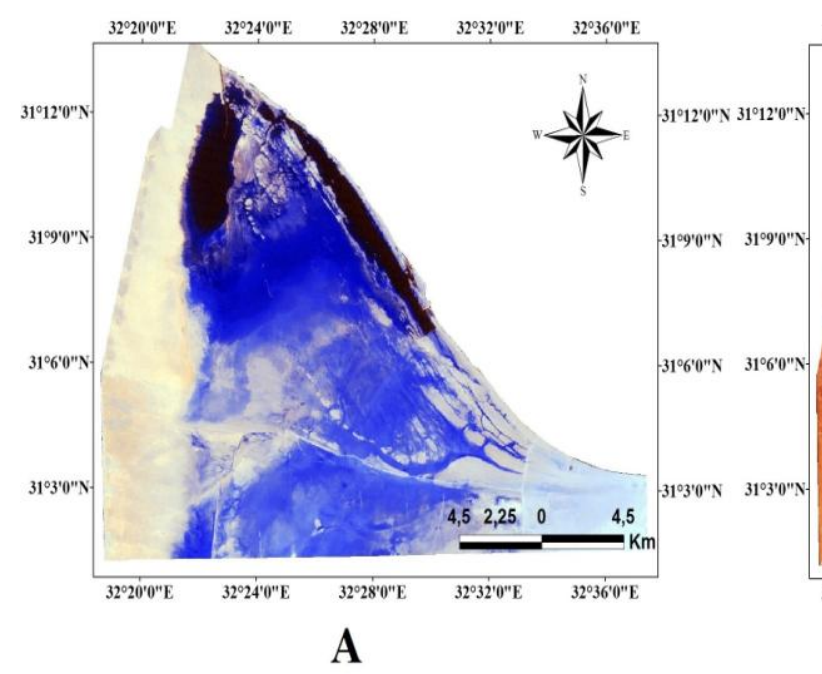

1984

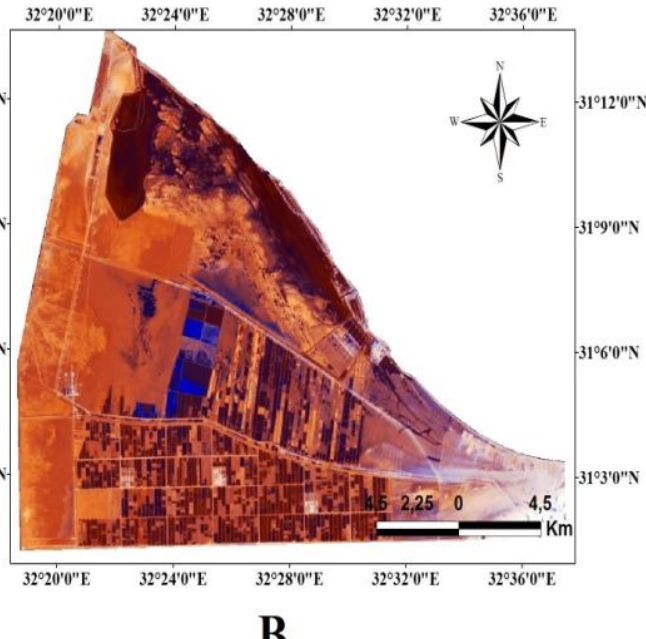

2015

Fig (3): Band ratios of 7/4, 7/2, and 4/2 (red, green, and blue) for 1984 (A) and 2015 (B)

\subsubsection{Principal component analyses (PCA):}

PCA of the Landsat TM data of El-Tina coastal plain area was applied on its seven bands. A set of three-band PC color composites was created. The false color composite images were utilized as input images to produce PCs representing all changes occurred during 1972-1991 [10]. This method was employed instead of using the whole data sets as an input for principal components analysis. Visual inspection of the PC color composites indicates that the composite containing the first three PCs was the most informative. Additional clarification was provided by noise reduction and the elimination of inter-band correlations. Statistical analysis indicates that PC1 yielded the highest positive correlations in band 7. Features with the highest reflectivity in band 7 are best represented by PC1. PC2 showed high positive correlation in band 4 and would be useful for a vegetation study. Therefore, the image produced from combining bands PC1 (red), PC2 (green) and PC3 (blue) is representative of specific ground features, and demonstrates the best contrast among the major features of the study area; water bodies, cultivated areas, wetland areas and salt crust (Fig 4). From 1984 to 2015, El-Mallaha Lagoon and surrounding sabkha have been decreased in size while the area covered by cultivated and fish farms as well as wet land increased.

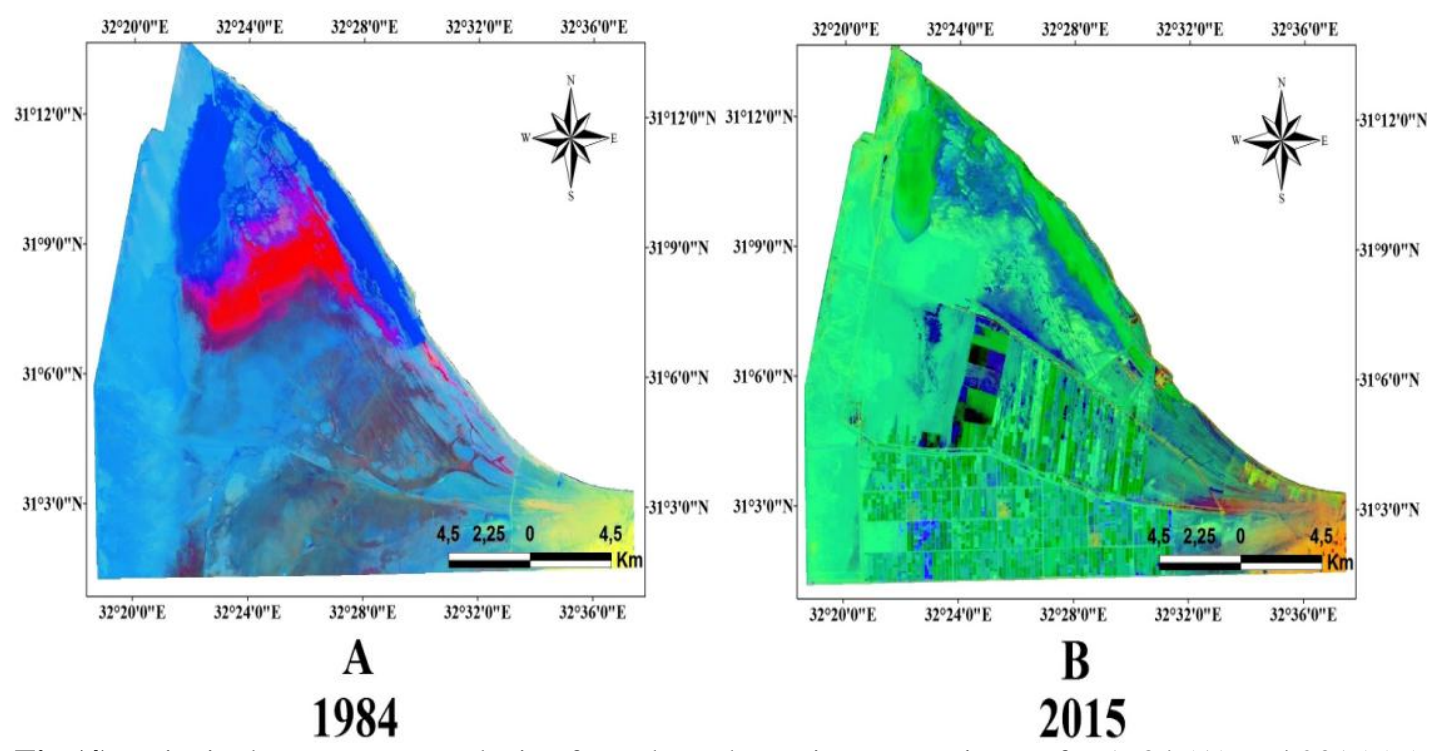

Fig (4): Principal component analysis of Landsat Thematic Mapper image for 1984 (A) and 2015 (B) 


\subsubsection{Data Fusion (Resolution merge):}

Image fusion is the spatial enhancement technique to make the best use of different complementary information from multi-source and multi-temporal imagery. Various techniques of image fusion (sometimes called merging or sharpening) have been developed by scientist and software [1]. The most common are PC (Principal Component) Spectral as mention above and Gram-Schmidt. A multi-spectral image can be fused with a higher resolution panchromatic (pan) image to create the high resolution multi-spectral (MS) image [35]. However, it can also be used for fusing optical with a higher resolution microwave data [37]. The resulting fused image will have more information than the input image. This is common practice in almost all kind of LULC studies especially when high resolution MS data are unavailable due to various limitations.

Before running the fusion, it has to be kept in mind that both images should have registered in a common reference system and they should matched pixel-to-pixel without any displacement of the same features within the images. In case of fusion multi-spectral image with a higher resolution panchromatic (pan) image to create the high resolution multi-spectral (MS) image there is no problem but when fusing optical with a higher microwave data such as Radar-sat data you should make image registration initially. Image registration is the processes of finding a mapping function that maps one image space into the other such that each pixel at the same position in the two images corresponds to the same point in the imaged scene. The goal of image registration is to establish the correspondence between two images and determine the geometric transformation that aligns one image with the other. Based on a correlation between the two Images by using well distributed ground control points (GCP). Accuracy of the feature-based registration methods depends largely on the accuracy of the selected GCP points. Point-based image registration is achieved by finding a set of points from one image into the same corresponding points in the other image.

The objective of this process is to merge optical data with a high resolution microwave data. Hyperspectral data sets can be classified (Unsupervised and Supervised classification) and then compare the fused optical/microwave classified image with fused optical/ panchromatic classified image. Figure (5) is shown the fused optical/ panchromatic image and fused optical/ microwave image.

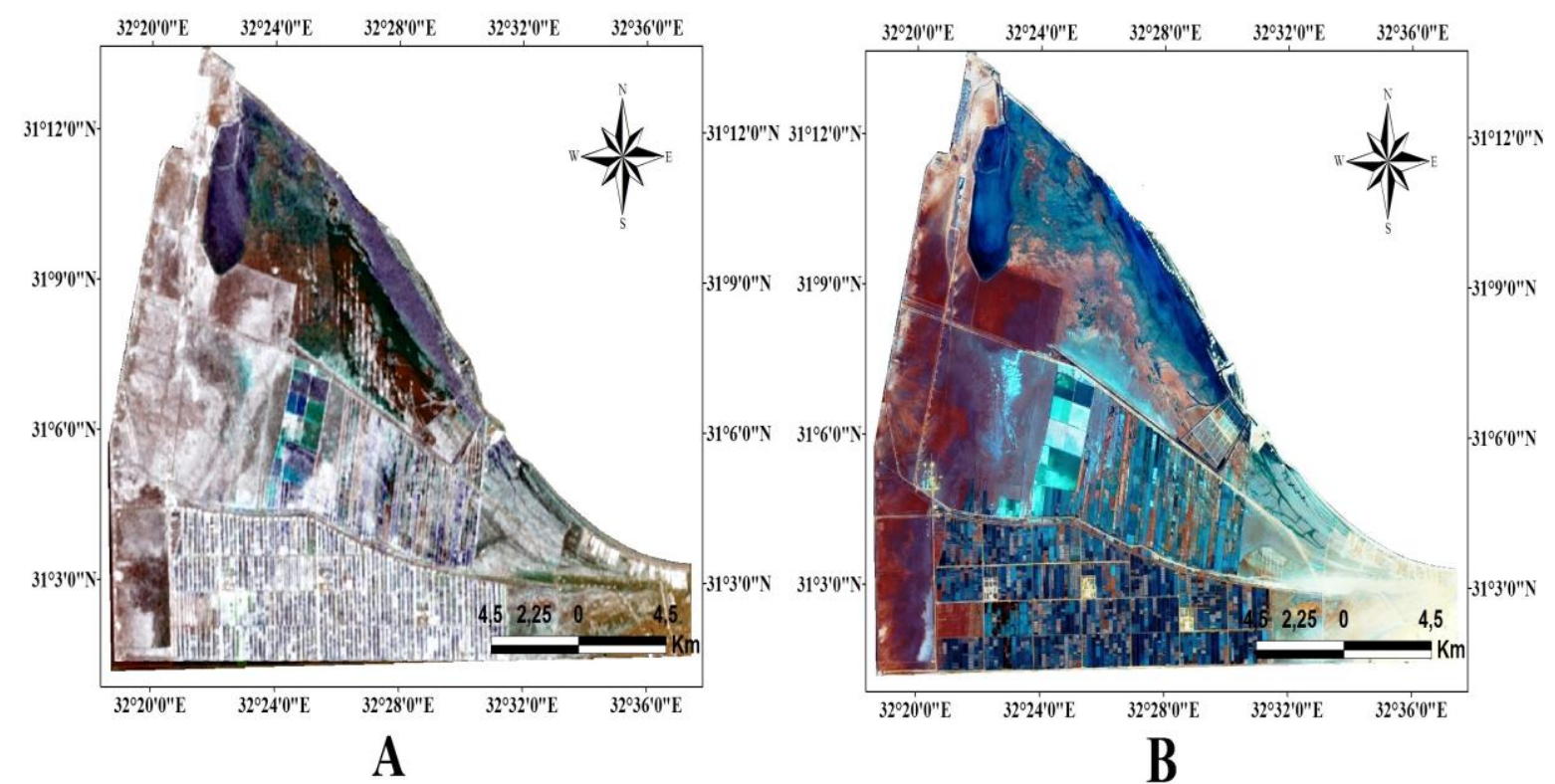

Fig (5): (A) Fused image of Landsat ETM+ (2015) (bands 7, 4, 2 as RGB) with Radarsat-1(2010) and (B) Fused image of Landsat ETM+ (2015) (bands 7, 4, 2 as RGB) with panchromatic band (2015)

\subsubsection{Image classification for Land Use / Land Cover: \\ 4.1.3.1 Unsupervised classification:}

Unsupervised classification occurred when the analysis is controlled by the computer program. The training process uses the computer to calculate a specific spectral signature on which the classification process will be based. Each signature is supposed to correspond to a class. Using a specific equation (classification algorithm) tests every pixel on the image and 0 assigns it to a specific class. In unsupervised training the analysts enter some parameters that will be used to detect statistical classes inherent in the data. These classes do not necessarily correspond to real classes on the ground or any other features in the area represented by the image. They are simply determined mathematically. Some of the produced classes may need to be merged 
together, while others may need to be deleted. Figure (6) is show the hyperspectral (fused optical/microwave), 1984 and 2015 images that classified into 10 classes by Envi 4.7 program.
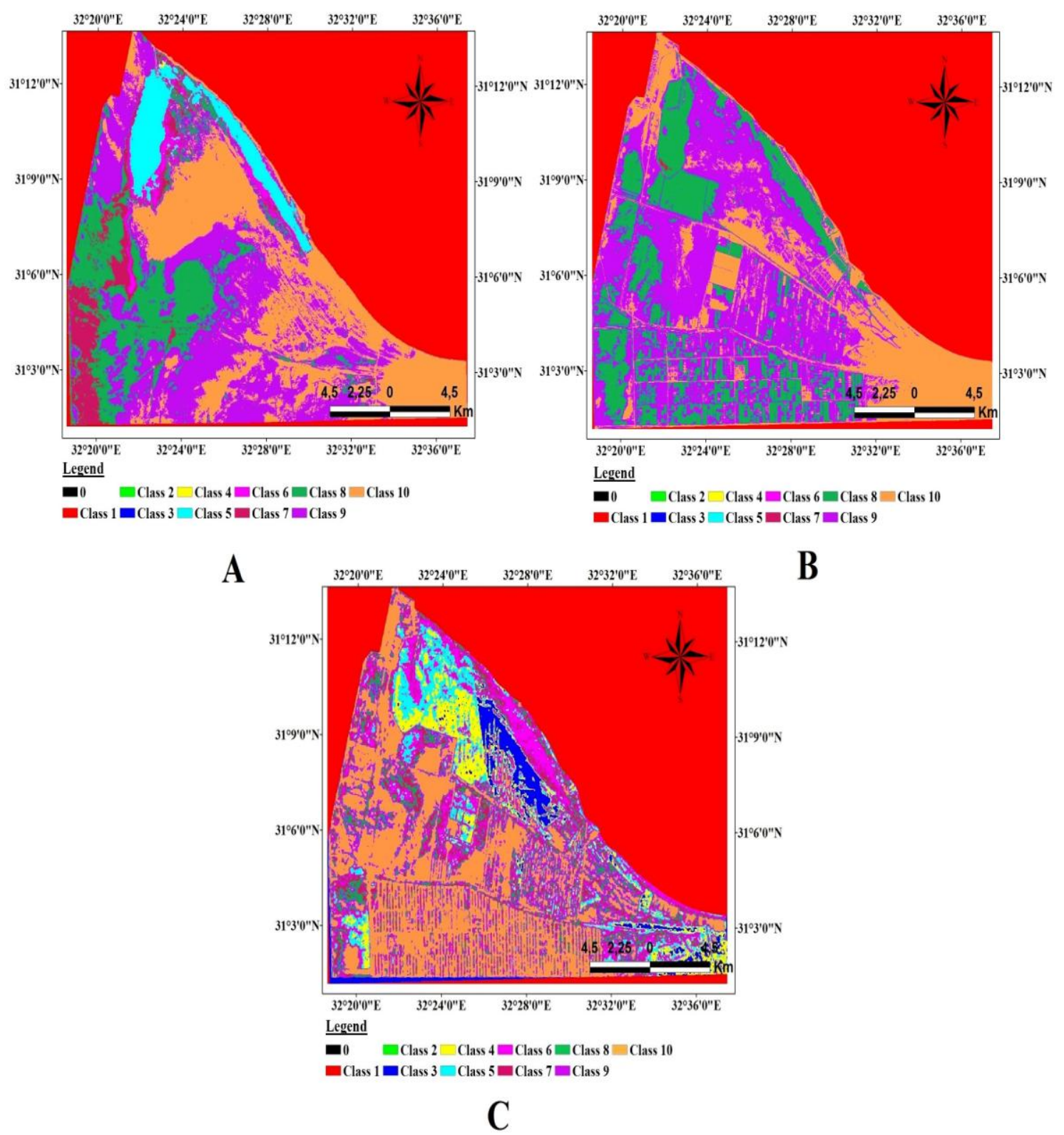

Fig (6): Unsupervised classification for 1984 image (A), 2015 image (B) and fused image (Landsat ETM+ 2015 with Radarsat-1 2010) (C)

\subsubsection{Supervised classification:}

Supervised classification is closely controlled by the analyst who chooses a group of pixels in the image to represent the criteria of each class. Supervised classification was completed for each date using field investigation information collected from more than 30 ground checkpoints and digital topographic maps of the study area.

The analysis of LU/ LC of the study area between 1984, 2015 and fused (optical/ microwave) reveals seven major classes (Fig 7) that were verified in the field. These classes are cultivated land, fish farms, clay, sabkha (salt), sand, wetland and surface water (El-Mallaha Lagoon). No human activities (cultivated land) were observed on the image 1984 (Fig 7). In 1984, the area of El-Mallaha lagoon was $26 \mathrm{~km}^{2}$, the sabkha (salt) area was $224.5 \mathrm{~km}^{2}$, clay area was $93.2 \mathrm{~km}^{2}$, sand area was $24.9 \mathrm{~km}^{2}$ and wet land area was $11.3 \mathrm{~km}^{2}$. The development activities came later on 1991 and well developed by year 2000 after excavation of El- Salam (Peace) Canal, and the establishment of the mega-project of development communities targeting reclamation and cultivation of 400000 ac. east of the Suez Canal. 
In 2015 and using the fused image (Optical/microwave), the development activities obviously reflected in cultivated land and fish farm that reached $75.6 \mathrm{~km}^{2}$ and $23.4 \mathrm{~km}^{2}$ and concentrated to the south of the study area. Surface water area (El-Mallaha Lagoon) decreased (Table 1) and clay increased as a result of increased sedimentation. However, sabkha (Salt) area decreased and wetlands increased.

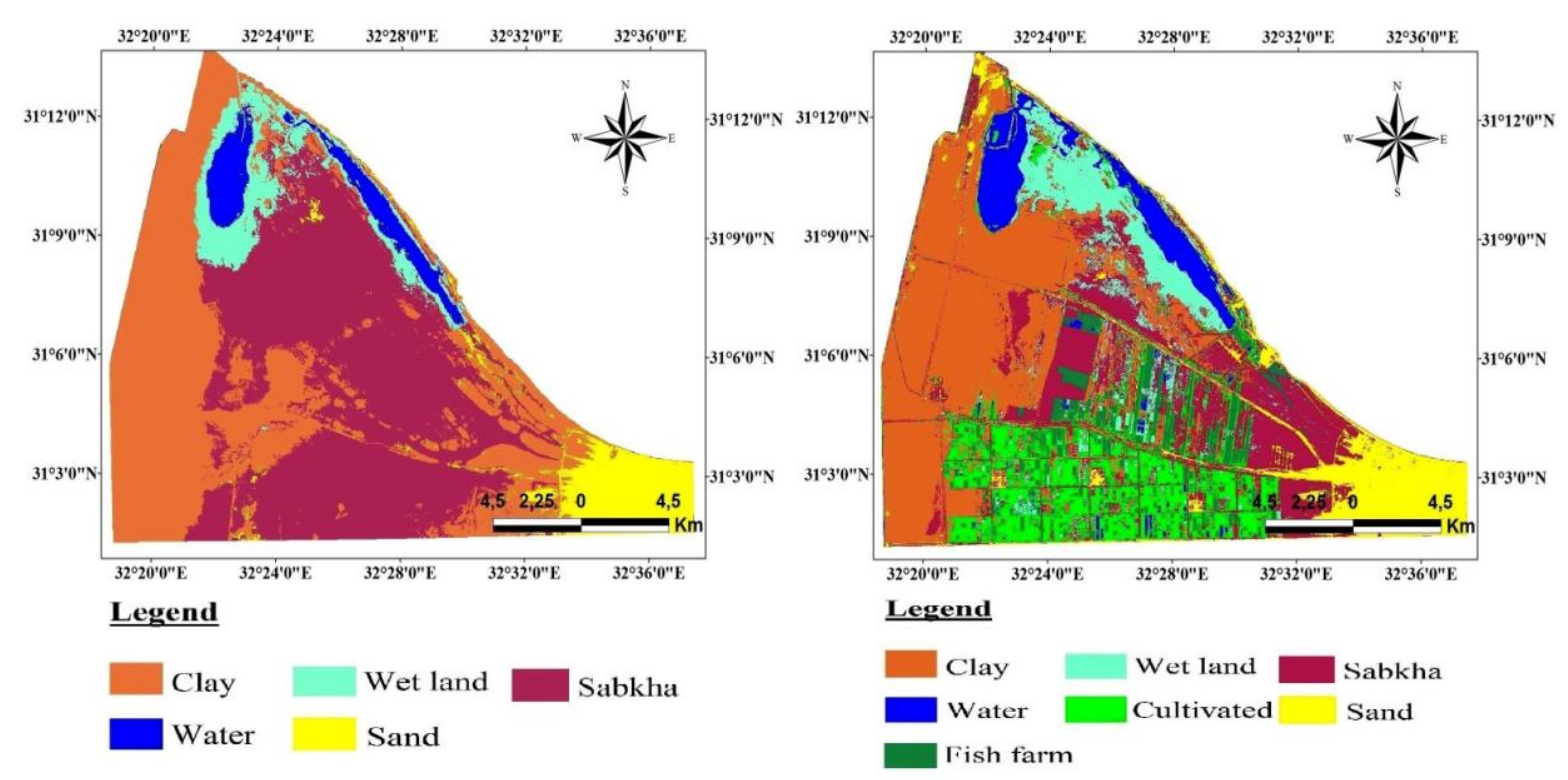

A

B

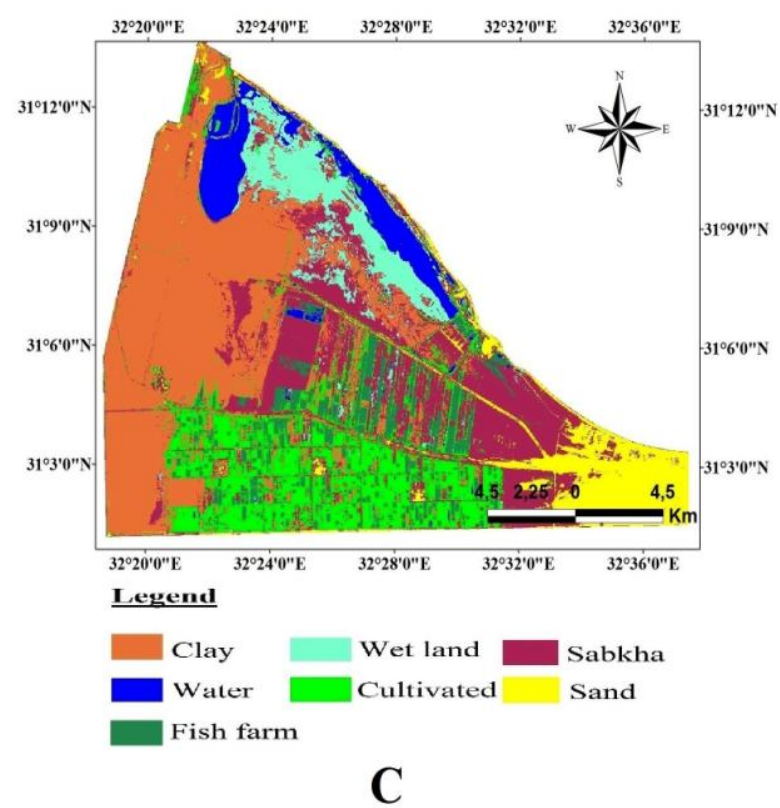

Fig (7): Supervised classification for 1984 image (A), 2015 image (B) and fused image (Landsat ETM+ 2015 with Radarsat-1 2010) (C)

Table (1): Change in areas of different land cover classes of 1984 and 2015 classified images.

\begin{tabular}{|l|c|c|}
\hline & \multicolumn{2}{|c|}{$\mathrm{Km}^{2}$} \\
\hline Year & $\mathbf{1 9 8 4}$ & $\mathbf{2 0 1 5}$ \\
\hline Water & 26 & 23 \\
\hline Wet Land & 11.3 & 36.3 \\
\hline Sabkha & 224.5 & 54.6 \\
\hline Clay & 93.2 & 125.2 \\
\hline Sand & 24.9 & 41.8 \\
\hline Fish Farm & not exist & 23.4 \\
\hline Cultivated land & not exist & 75.6 \\
\hline
\end{tabular}




\subsubsection{Post classification:}

Finally, class statistics of each classified image were computed in ENVI. Following this, a majority/minority filter with an operating window size of 5 by 5 was performed in ENVI. A majority filter is a logical filter applied on a classified image. Then, the number of pixels allocated to each of the classes is counted and, if the center pixel is not a member of the majority class (containing five or more pixels within the window) it is given the label of the majority class. The effect of this algorithm is to smooth the classified image by weeding-out isolated pixels, which were initially given labels that were dissimilar to the labels assigned to the surrounding pixels [23]. Figure (8) shows the 1984, 2015 and fused (optical/microwave) images after majority/ minority step.

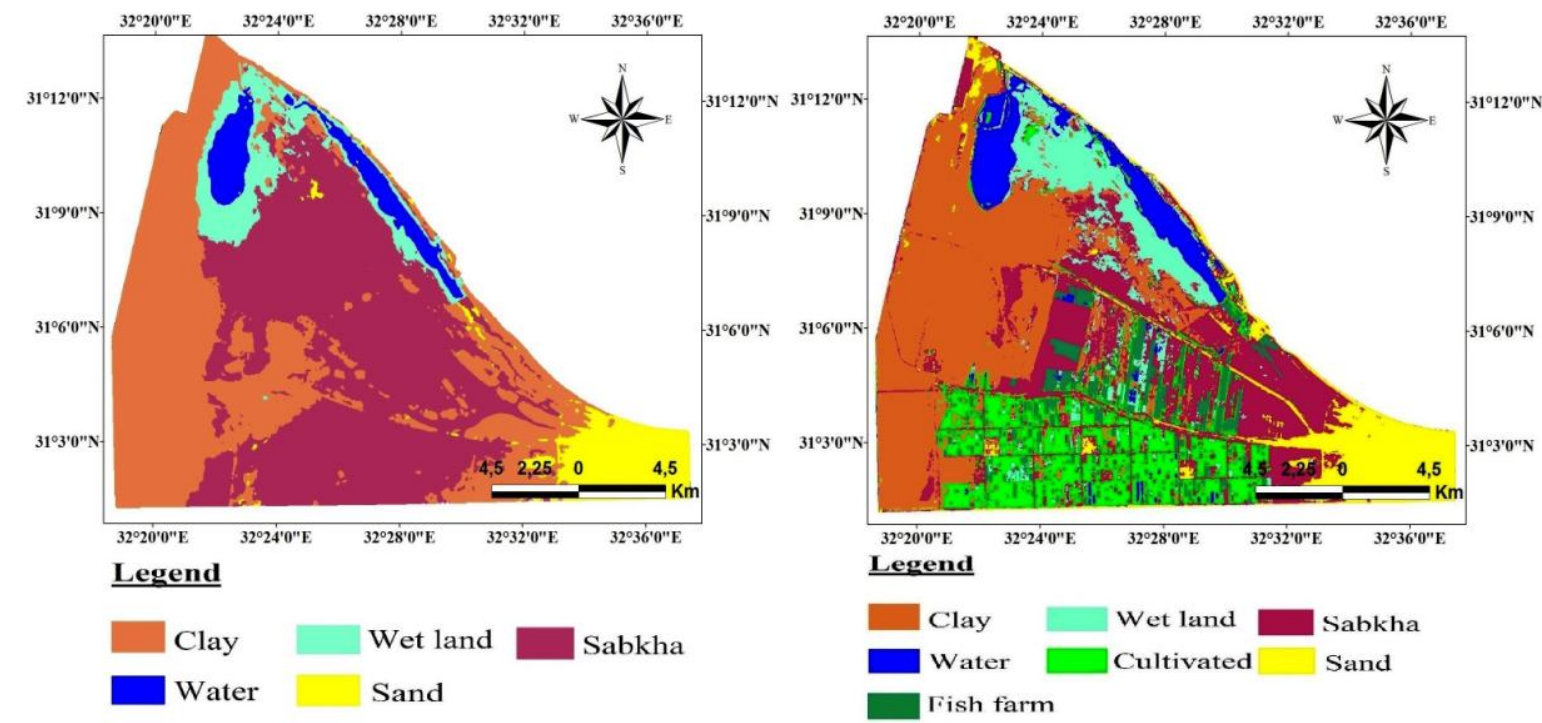

A

B

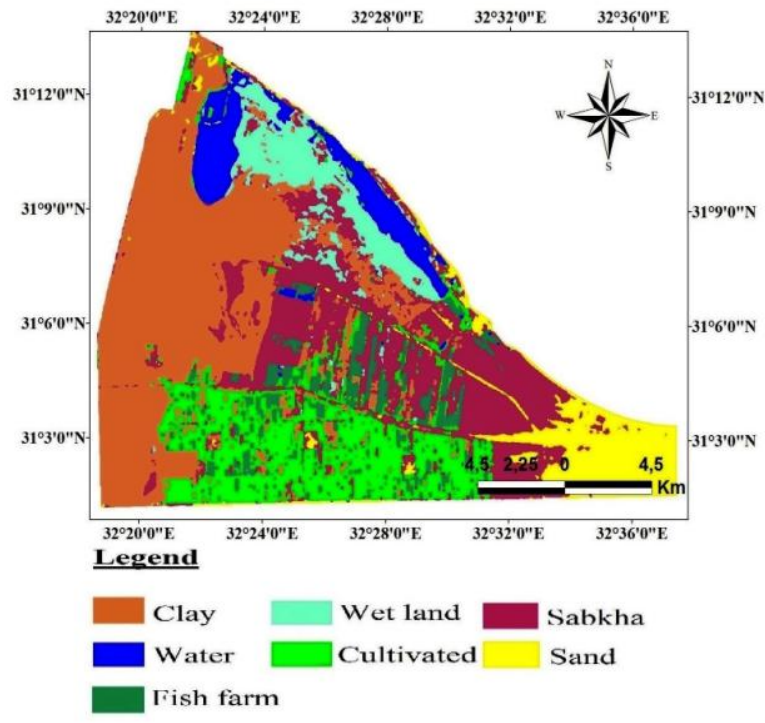

C

Fig (8): Post-Classification (Majority/Minority) using 1984 image (A), 2015 image (B) and fused image (Landsat ETM+ 2015 with Radarsat-1 2010) (C)

\subsubsection{Accuracy assessment:}

The best way for checking the result of classification is to check everything in each class which can be realized in Envi by the function of classification accuracy assessment. To distribute the random points exactly from every class, the equalized random was chosen for distribution of parameters and the number of random samples was set as 200 reference points. Each point on the images was given by a class code in reference column. Then the class values were shown for checking the agreements. The results were represented in tabular 
with error matrices. In the error matrices, the procedure' accuracy refers to the ratio which is calculated by the number of correct classified pixels in one class dividing the total number of referenced pixels of this class; the user's accuracy refers to the ratio which is calculated by the number of correct classified pixels in one class dividing the total number of classified pixels in this class; the overall classification accuracy is calculated by the number of correct classified pixels dividing the total number of classified pixels; the coefficient is often used for estimating the accuracy of the classification [1]. The accuracy statistics of the three generated classification images 1984, 2015 and fused (optical/microwave) imaged was 93\%, 94.6\% and 95\%, respectively. Therefore, the classified maps from supervised classification were acceptable.

\section{Conclusion}

The present study is an attempt to show the surface changes in the area of East Port-Said during 1984 2015. To achieve this study, satellite data acquired for years 1984 and 2015. In addition, several field verification and lithofacies description were conducted. The observed land use/land cover changes were caused by several factors. The study area has been subjected to intensive local planning and development projects such as construction of the El-Salam Canal, the creation of the East Port Said harbour, an increase in industrialization, fish farms and reclamation. Change detection of LU/LC show seven classes; water bodies, wet land, sabkha or salt marshes, clay, cultivated land, and fish breeding farms and sand. In 1984, water bodies (26 $\mathrm{km}^{2}$ ), wet land $\left(11.3 \mathrm{~km}^{2}\right)$, sabkha or salt marches $\left(224.5 \mathrm{~km}^{2}\right)$, clay $\left(93.2 \mathrm{~km}^{2}\right)$ and sand $\left(24.9 \mathrm{~km}^{2}\right)$. In 2015 and using the fused image (Optical/microwave), the development activities obviously reflected in cultivated land and fish farm that reached $75.6 \mathrm{~km}^{2}$ and $23.4 \mathrm{~km}^{2}$ and concentrated to the south of the study area. Water bodies decreased to $23 \mathrm{~km}^{2}$ (Table 1) and clay increased to $125.2 \mathrm{~km}^{2}$ as a result of increased sedimentation. However, sabkha (Salt) area decreased and wetlands increased.

\section{References}

[1] Bakr, N., Weindorf, D.C., Bahnassy, M.H., Marei, S. M., EI-Badawi, M.M.. Monitoring land cover changes in a newly reclaimed area of Egypt using multi-temporal Landsat data, Applied Geography, 30(4), 2010, 592-605.

[2] Carper W., Lillesand M., and Kiefer R., The use of intensity-hue-saturation transformations for merging SPOT pan and multispectral image data, Photogrammetric Engineering \& Remote Sensing, 56 (4), 1990, 459-467.

[3] Csillage, F.. Comparison of some classification methods on a set site (Kiskore, Hungary): separability as a measure of accuracy. International Journal of Remote Sensing, 7, 1986 1705-1714.

[4] Dewidar K.H.M., Frihy O.E.. Thematic Mapper analysis to identify geomorphologic and sediment texture of El-Tineh plain north western coast of Sinai, Egypt. Int J Remote Sens 24, 2003, 2377-2385.

[5] Dewidar K.H.M.. Landfilling detection of Hurghada, North Red Sea, Egypt, by using Thematic Mapper. International Journal of Remote Sensing, 23, 2000, 939-948.

[6] Dewidar K.H.M.. Detection of the land use/land cover changes for the northern part of the Nile delta (Burullus region), Egypt. International Journal of Remote Sensing, 25(20), 2004, 4079-4089.

[7] Eklundh L., \& Singh A.. A comparative analysis of standardized and unstandardized principal components analysis in remote sensing. International Journal of Remote Sensing, 14, 1993, 1359-1370.

[8] El-Asmar H.M.. Late Holocene stratigraphy and lithofacies evolution of the Tineh plain North western corner of Sinai, Egypt. Egypt J Geol 43(2), 1999, 119-134.

[9] El-Asmar H.M., Taha M.M.N., El-Kafrawy S.B., El-Sorogy A.S.. Control of Late Holocene Geo-processes on the sustainable development plans of the Tineh Plain, NW Sinai coast, Egypt. J Coast Conserv, 19(2), 2015, 141-156.

[10] El-Raey M., Nasr, S. M., \& El-Hattab, M. M.. Change detection of Rosetta promontory over the last forty years. International Journal of Remote Sensing, 16(5), 1995, 825-834.

[11] ENVI (Environment for Visualizing Images); ITT Visual Information Solutions: USA, 2008.

[12] Frihy O.E., Lotfy M.F.. Shoreline changes and beach-sand sorting along the northern Sinai coast of Egypt. Geo-Mar Lett 17, 1997, $140-146$.

[13] Fung T., \& LeDrew, E.. Application of principal components analysis change detection. Photogrammetric Engineering and Remote Sensing, 53, 1987, 1649-1658.

[14] Gaber A., Koch M., El-Baz, F.. Textural and Compositional Characterization of Wadi Feiran Deposits, Sinai Peninsula, Egypt, Using Radarsat-1, PALSAR, SRTM and ETM+ Data. Remote Sens., 2, 2010, 52-75.

[15] Goodfriend G.A., Stanley D.J.. Rapid strand-plain accretion in the northeastern Nile Delta in the 9th century AD and the demise of the port of Pelusium. Geology 27, 1999, 147-150.

[16] Hixon M.M., Davis, B.J., \& Bauer, M.E.. Sampling Landsat classification for crop area estimation. Photogrammetric Engineering and Remote Sensing, 47, 1981, 1343-1348.

[17] Howarth P.J., \& Boasson E.. Landsat digital enhancement for change detection in urban environment. Remote Sensing of Environment, 13, 1983, 149-160.

[18] Howarth P.J., \& Wickmore, G.M.. Change detection in the Peace-Athabasca delta using digital Landsat data. Remote Sensing of Environment, 11, 1981, 9-25.

[19] Jensen J.R.. Introductory Digital Image Processing: A Remote Sensing Perspective, 2nd edition, Prentice Hall PTR. Journal of Remote Sensing, 14, 1995, 1359-1370.

[20] Kaiser M.. Environmental changes, remote sensing, and infrastructure development: the case of Egypt's East Port Said harbour. Appl Geogr 29, 2009, 280-2880.

[21] Lillesand T.M., Kiefer, R.W., \& Chipman, J.W.. Remote sensing and image interpretation. John Wiley \& Sons., $2004,763$.

[22] Mather P.M.. Computer processing of remotely-sensing images, an introduction (2nd ed.). Chichester: John Wiley and Sons., 1999, $1-75$.

[23] Mather P.M.. Computer Processing of Remotely-Sensed Images: an Introduction, 3rd Edition. John Wiley \& Sons Ltd, Chichester, England, 2004. 
[24] Nelson R.F.. Detecting forest canopy change due to insect activity using Landsat MSS. Photogrammetric Engineering and Remote Sensing, 49, 1983, 1303-1314.

[25] Picchiotti A., Casacchia, R., \& Salvatori, R.. Multi-temporal principal component analysis of spectral and spatial features of the Venice Lagoon. International Journal of Remote Sensing, 18(1), 1997, 183-196.

[26] Richards J.A.. Remote sensing digital image analysis: An introduction. Berlin: Spring-Verlag, 1993.

[27] Sabins F.F.. Remote sensing principles and interpretation. New York: W.H. Freeman, 1987.

[28] Salem B.B., El-Cibahy A., \& El-Raey M.. Detection of land cover classes in agro-ecosystems of northern Egypt by remote sensing. International Journal of Remote Sensing, 16(14), 1995, 2518-2594.

[29] Shalaby A., \& Tateishi, R.. Remote Sensing and GIS for mapping and monitoring land cover and land-use changes in the Northwestern coastal zone of Egypt. Applied Geography, 27, 2007, 28-41.

[30] Singh A., \& Harrison A.. Standardized principal components. International Journal of Remote Sensing, 6, $1987,883-896$.

[31] Stanley D.J.. Subsidence in the northeastern Nile Delta: rapid rates, possible cause, and consequence. Science 240, 1988, 497-500.

[32] Stanley D.J, Bernasconi M.P., Jorstadt T.F.. Pelusium, an ancient port fortress on Egypt's Nile Delta coast: it's evolving environmental setting from foundation to demise. J Coast Res., 24(2), 2008, 451-462.

[33] Thomas I.L., Benning V.M., \& Ching N.P. (Eds.).. Classification of remotely sensed images. Bristol: Adam Hilger, 1987.

[34] Todd W. J.. Urban and regional land use change detection by using Landsat data. Journal of Research US Geological Survey, 5, 1977, 529-534.

[35] Welch R., Ahlers W.. Merging multire-solution SPOT HRV and Landsat TM data. Photogramm. Eng. Remote Sens., 53, 1987, 301303 .

[36] Wilson J. R., Blackman C., \& Spann G.W.. Land use change detection using Landsat data. Proceedings of the Fifth Annual Remote Sensing of Earth Resources Conference, 1976, Tullahoma, Tennessee, p. 91

[37] Xie H., Keller G.R.. Fusion of Landsat ETM+ and radar data to enhance the extraction of surface and near-surface information. Geol. Soc. Amer., 397, 2006, 141-151. 